\title{
CARMELA CIOFFI, L'ANDRIA DI TERENZIO. COMMENTO FILOLOGICO LETTERARIO (TESTI E COMMENTI, 26), PISA, EDIZIONI DELLA NORMALE, 2020, 1034 PP. ISBN 978-88-7642-685-8.
}

\author{
MARC MAYER I OLIVE \\ Universitat de Barcelona \\ mayerolive@yahoo.es \\ ORCID: 0000-0003-1293-7928
}

El volumen tan voluminoso, valga la redundancia, como el que tenemos ante nosotros desmiente el proverbio de que un libro grande equivale a una gran desgracia. Nos hallamos ante la monografía de referencia para esta obra de Terencio para los próximos años y, por lo que respecta a la fijación del texto y a la tradición manuscrita, ante un elemento indispensable para el conjunto de la obra de Terencio.

El libro se articula en tres partes fundamentales: una introducción, un elenco de los testimonios sobre la Andria y un detenido comentario.

En la introducción, la autora se ocupa en primer lugar del argumento, la estructura y las contradicciones que presenta esta comedia. También se hace un elenco de los personajes y sus características, y se ofrece un repaso sumario de lo que denomina prácticas teatrales, que van desde las fechas de representación hasta la forma en que se presentaban los actores.

Merece especial atención el apartado dedicado a «L'Andria ed Il metateatro in Terenzio», donde hace una precisión inicial que no se puede pasar por alto: «Nell'Andria il vero e propio motore dell'azione è costituito dalla dialettica continua tra tradizione ed innovazione, in cui spesso l'innovazione costituisce un allontanamento da Plauto ed un ritorno a Menandro». Sigue a continuación una selección de pasajes y escenas en las que la estudiosa observa diversos casos de aplicación de técnicas teatrales, para entrar a continuación a tratar la relación entre Terencio y Menandro y el recurso a la contaminatio en la obra. Un quizás demasiado rápido recorrido por el camino de la fortuna de Terencio da paso a un aspecto que no puede faltar en los estudios terencianos como es el de las representaciones de la obra. Más extenso es el tratamiento de las características lingüísticas y estilísticas con atención también al léxico. Las cuestiones métricas y la prosodia del texto de Terencio no podían faltar en esta introducción y C. Cioffi realiza un análisis de manera competente y sintética. Se pasa con ello a uno de los aspectos más interesantes: una revisión de la tradición manuscrita, la constitutio textus y los criterios de edición. Hay que detenerse en este punto, ya que sin pretender introducir novedades da una visión crítica y bien informada de las fuentes manuscritas y de los problemas que en la mayor parte de los casos tan sólo señala, indicando la referencia bibliográfica donde seguir el problema o 
el desarrollo de la cuestión. Quizás en este punto, a pesar de la buena documentación aducida, el lector hubiera agradecido algo más que una pincelada sobre algunas cuestiones críticas trascendentes, como la relación entre las tradiciones textuales $\delta$ y $\gamma$, así como también la precoz formación de una vulgata. No falta una sumaria mención a los hallazgos papiráceos y sobre todo una alusión a la importancia de la tradición indirecta y a la influencia de la obra de Terencio en las escuelas y entre los gramáticos, temas para los cuales son esenciales los trabajos de Velaza y Monda.

La edición que la autora sigue como base para su propio texto es la oxoniense de Kauer y Lindsay y la puesta al día de Skutsch. Sin embargo, tal y como indica la propia autora, sin pretender hacer una nueva edición crítica, C. Cioffi ha establecido lo que denomina un «testo di lavoro», que no depende de colaciones de texto directas más que en algunos casos, pero que sin duda nos permite acceder con facilidad a un número crecido de informaciones, que como ya habíamos anunciado constituye uno de los puntos fuertes de esta edición, con todas las salvedades que ha querido precisar la editora especialmente en lo que concierne a la nutrida tradición indirecta.

Además, Cioffi documenta con precisión la exclusión del pasaje conocido como «alter exitus», que como es sabido completa el texto de Terencio con un happy end con la boda de Carino y Filumena.

Sumario también en los límites prefijados es el tratamiento de las didascalia y los argumenta o Periocha de Sulpicio Apolinar, especialmente en lo concerniente a la obra editada y comentada: la Andria.

Sigue a continuación la edición del texto latino de la obra con el importante aparato crítico del que hemos hecho ya mención, con las particularidades, características y limitaciones que su editora ha precisado con gran claridad y honestidad.

A la edición del texto se suma el comentario que ocupa, junto con la bibliografía, las cerca de mil páginas siguientes.

Destacaremos del comentario la detenida exposición y análisis del contenido y función del prólogo, que constituye propiamente una monografía sobre la cuestión.

El comentario está organizado siguiendo el orden de actos y escenas, y dentro de cada una de ellas se van introduciendo los pasajes o términos a comentar con indicación del número de verso. Conviene señalar que el comentario introduce también los loci parallelli respecto a otros autores y a la propia obra de Terencio, además de las noticias recogidas en los comentarios antiguos. Hemos de hacer hincapié en la atención que presta la autora del a los aspectos estilístico, que muchas veces la hacen incidir en cuestiones relacionadas con la interpretación del contenido del propio texto terenciano, lo cual resulta de singular utilidad. No se esquiva, como ya se ha notado al ocuparnos de la introducción, el comentario lingüístico y sintáctico, que tiene una muy especial relevancia en muchos casos y que hace que este volumen constituya también, 
más que una aproximación, un estudio muy completo de la lengua de Terencio y sus particularidades. Lo mismo podemos decir de los aspectos léxicos.

Como no podía ser de otro modo, cada entrada a comentar refleja la correspondiente anotación crítica del texto en el caso en que sea significativa. Desde un punto de vista propiamente literario, el extenso comentario reproduce la práctica totalidad de las aportaciones de los comentarios anteriores. La redacción es sobria sin prolijas explicaciones innecesarias, ordenada y ceñida al comentario estricto sin digresiones sobre otros temas o autores, lo que resulta muy de agradecer dadas las dimensiones de la obra, y la posibilidad consiguiente de perderse o desviarse por otros derroteros, por interesantes que éstos sean, en los comentarios, como sucede en otras ocasiones. La lectura resulta, pues, relativamente ágil e incluso muy agradable especialmente cuando se trata de la interpretación de la obra en la que no se evitan comentarios que podríamos casi considerar «psicológicos» sobre los estados de ánimo de los personajes que refleja el texto de la Andria. Lo mismo podemos decir de la excelente descripción de las situaciones escénicas.

En suma, cuando llegamos al plaudite, bien analizado al término del comentario, podemos decir, volviendo a cuanto hemos dicho ya al iniciar nuestro texto, que nos hallamos ante una aportación llamada a ser una autoridad y un referente para el tema en los años venideros y que no podemos menos que felicitar a quien ha emprendido esta tarea con evidente éxito.

Las casi cien páginas de bibliografía permiten seguir un estado de la cuestión terenciana, punto menos que completo, y denotan un trabajo intenso de documentación, así como una loable intención de exhaustividad. El hecho de que este esfuerzo de documentación no haya impedido que la autora redactara un texto mesurado y ceñido a los elementos que considera importantes es un motivo más para apreciar este volumen, que será seguramente indispensable no sólo para la Andria sino para toda la obra de Terencio. 